$R_{i}$

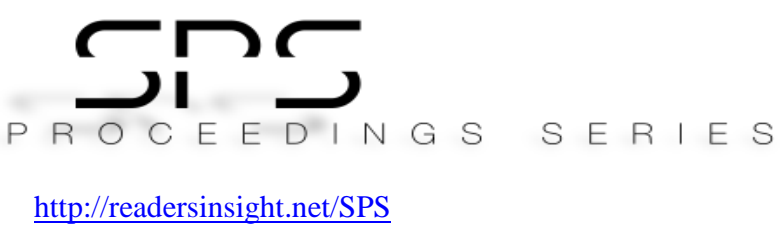

\title{
SIMPLE DESIGN AND CONTROL OF UNMANNED GROUND VEHICLE VIA ARDUINO AND ANDROID APPLICATION
}

\section{Safi Ullah Butt}

U.S.-PAKISTAN CENTER FOR ADVANCED STUDIES IN ENERGY National University of Science \& Technology

Pakistan

safibutt541@gmail.com

\author{
Abdul Rauf Bhatti * \\ Department of Electrical Engineering \\ Government College University Faisalabad \\ Pakistan \\ bhatti abdulrauf@gcuf.edu.pk, ORCID: 0000-0001-9609-4563
}

Bilal Ali

Department of Electrical Engineering

Government College University Faisalabad

Pakistan

bilalali6060@yahoo.com

\author{
Ali Bashir \\ Department of Electrical Engineering \\ Government College University Faisalabad \\ Pakistan \\ alibashir25643@gmail.com

\section{Muhammad Umar} \\ Department of Electrical Engineering \\ Government College University Faisalabad \\ Pakistan \\ umarrazzaq910@gmail.com

\section{Taufeeq Liaquat} \\ Department of Electrical Engineering \\ Government College University Faisalabad \\ Pakistan \\ taufeeqliaquat@gcuf.edu.pk
}




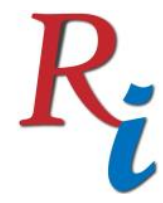

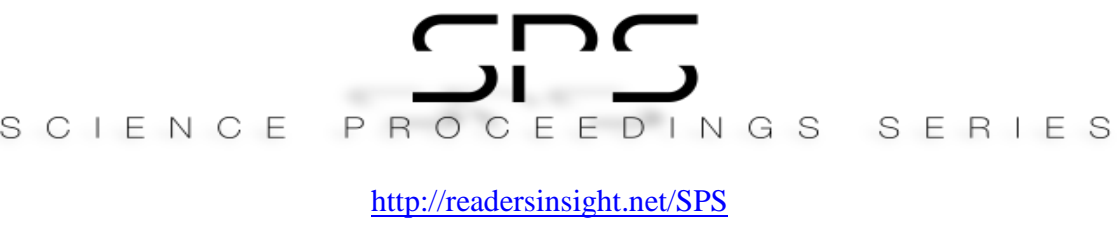

\section{A b s t r a c t}

This paper presents the design and implementation of unmanned ground vehicle (UGV) using a simple approach. An unmanned ground vehicle is an automobile without any onboard human presence. It is remotely controlled by an operator. It can be used in scenarios where the presence of human operator is inconvenient and dangerous. It is an Arduino and Android application based controlled vehicle. Bluetooth module (HC-06) provides the communication between the vehicle components and Android application. The motion of the vehicle is based on two DC gear motors that are connected to the rear wheels of the vehicle. The vehicle is equipped with the video camera (V380S) and a gun to provide live video stream to the operator and to fire in lethal situations respectively. The developed vehicle shows the possible usage of such prototype in security and military applications.

Keywords: Arduino; Bluetooth Module (HC-06); Camera (V380S); Unmanned Ground Vehicle; Design and Controlx

\section{Rese a r ch H igh I ight s}

$>$ Presents the design and implementation of unmanned ground vehicle (UGV)

$>\mathrm{UGV}$ can be used in scenarios where the presence of human operator is inconvenient and dangerous

$>$ Developed vehicle shows the possible usage of such prototype in security and military applications

\section{Graphical Abstract}

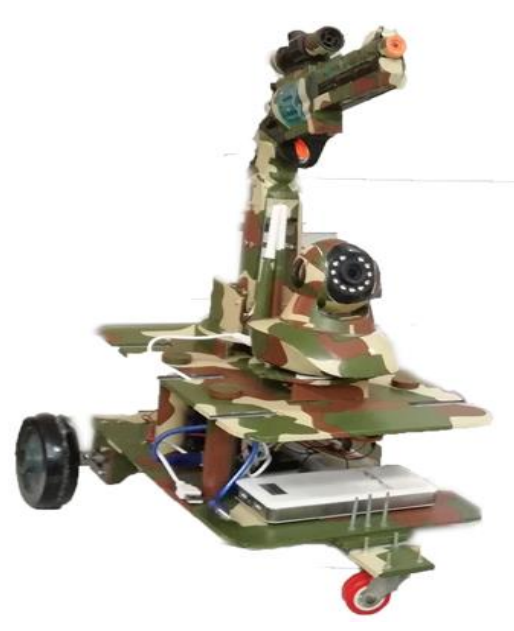




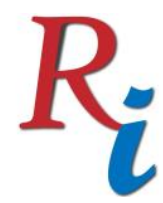

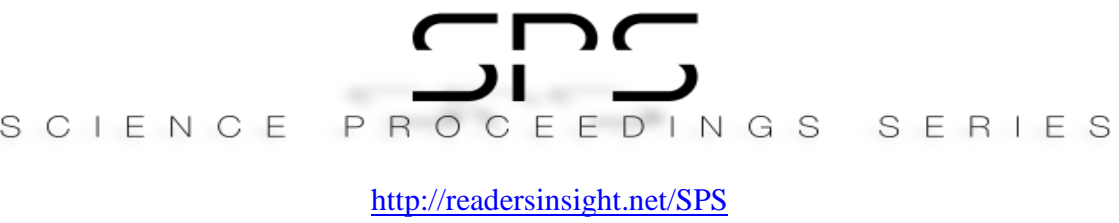

\section{Research Objectives}

An Unmanned Ground Vehicle (UGV) is an automobile without any onboard human presence (1). The main objective of this work is to develop a vehicle using simple approach for security applications where on board human presence may be inconvenient and unreliable. Android applications are very simple and popular for controlling robots (2) (3). This vehicle could be controlled via gadgets used in daily life e.g Android smart phones. The previous work on UGVs shows a complex architecture and communication system that is difficult to control (4) (5). Since the UGV is an automobile without any onboard human presence, this research presents a teleoperated vehicle that can be used to facilitate the humans in dangerous and inconvenient situations.

\section{Methodology}

It is an Arduino based electro-mechanical vehicle which is controlled and guided by an android smart phone using the Bluetooth feature. There are two major control requirements of the vehicle, first is control of the driving system and second is control of the shooting system. Both the controls are accomplished by Android application. Android application is connected to Arduino via Bluetooth module HC-06. HC-06 receives command from Android application and sends it to Arduino. There is a slider on the application to control the movement of camera and gun. The movement of camera and gun is synchronized with each other. Both of them receive same command from Arduino. A layout of Android application is shown in Figure 1.

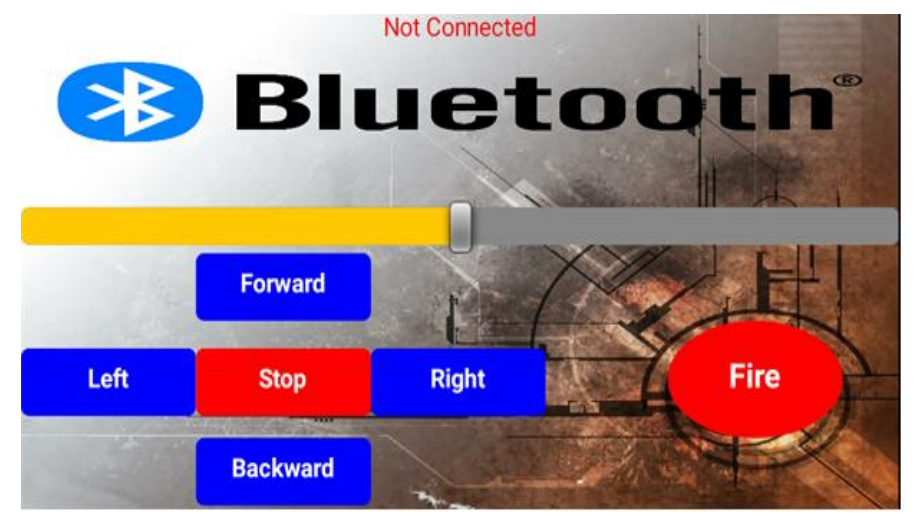

Figure 1: Application Preview

There is separate application to view live situation that camera is capturing. Camera has its own Wi-Fi system that can only be used by its application. Through this Wi-Fi system, user can view the live stream of the situation. The circuit implementation is shown in Figure 2. 


\section{$R_{i}$}
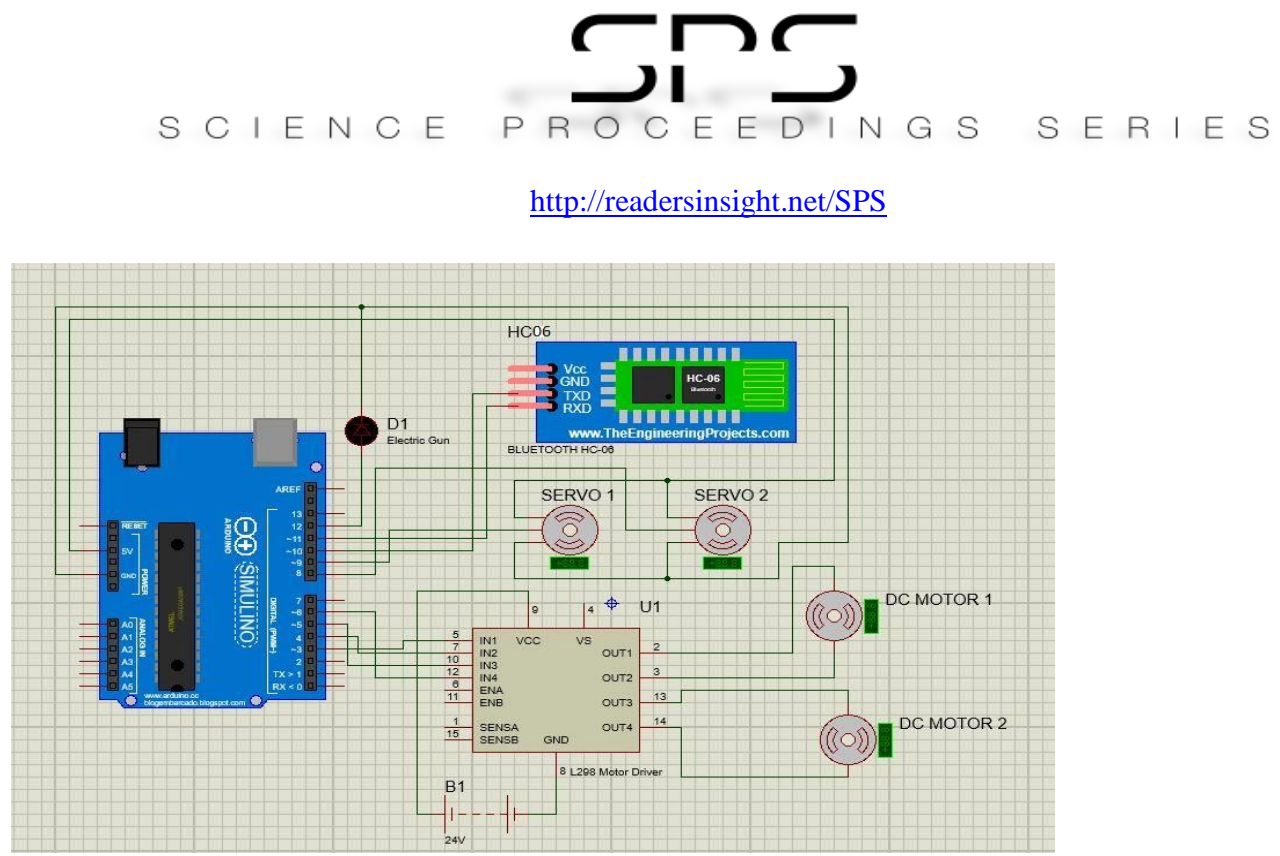

Figure 2: Circuit diagram of overall control system

\section{Results}

An unmanned ground vehicle has been manufactured with a simple but powerful design approach. The control of the vehicle is efficient and fast. Android application is the main gateway for controlling the working of the vehicle. Bluetooth module and Arduino are used to execute the commands from Android application. Wi-Fi communication is used to view the live situation from camera. Each component of the vehicle is tested separately. Camera, communication modules, driving of the vehicle is tested. The vehicle is fully functional and all components are working properly.

- The range of communication is around 10 meters. The realibility of communication in 10 meter distance is acceptable and reliable. The response time is found to be around 1 second that is quite good.

- The quality of the video from the camera is quite acceptable. Servo motors are found to provide proper rotation to camera and gun according to the slider command.

- The operation of DC gear motors is found to be reliable. No viberations and jerks are observed during the operation of the vehicle.

\section{Findings}

Functional tests were carried out and the main finding was the range of operation of the vehicle. Both Bluetooth module and camera can operate upto a range of $10 \mathrm{~m}$ which needs to be enhanced. The main purpose of this research is to realize the importance of smart living. Smart phones have become an important part of life. They can be easily integrated with security purposed vehicles. This project is an excellent demonstration for design and manufacturing of more sophisticated UGVs for different applications in the future. 


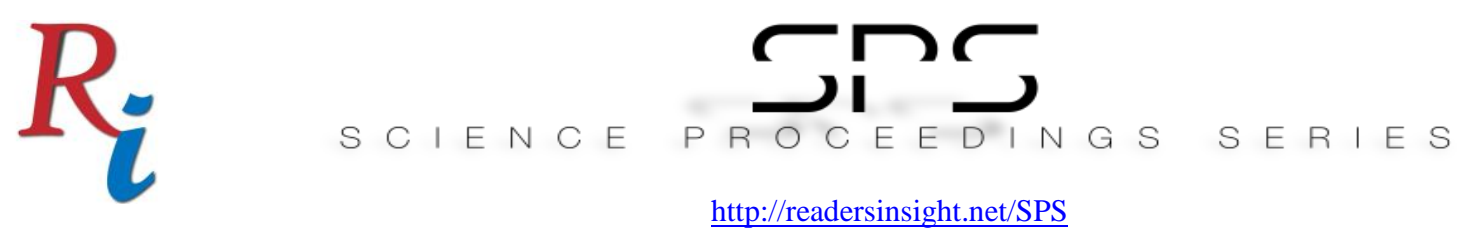

\section{Acknowledgement}

The authors are thankful to the Department of Elecftrical Engineering, Government College University Faisalabad for providing state-of-the-art laboratories to carry out the proposed work.

\section{REFERENCES}

[1] Zhao T, Jiang H. Landing system for AR.Drone 2.0 using onboard camera and ROS. In IEEE Chinese Guidance, Navigation and Control Conference (CGNCC); 2016; Nanjing,China.

[2] Stephan Gobel RJSLRaAZ. Using the Android Platform to control Robots. In IEEE; 2011. p. 1-8.

[3] Nádvorník J, Smutný P. Remote control robot using Android mobile device. In Proceedings of the 2014 15th International Carpathian Control Conference (ICCC); 2014; Velke Karlovice, Czech Republic.

[4] Bouhraoua A, Merah N, AlDajani M, ElShafei M. Design and implementation of an unmanned ground vehicle for security applications. In IEEE 7th International Symposium on Mechatronics and its Applications; 2010; Sharjah, United Arab.

[5] Barnes L, Fields M, Valavanis K. Unmanned ground vehicle swarm formation control using potential fields. In IEEE 2007 Mediterranean Conference on Control \& Automation; 2007; Athens, Greece.

Author's Biography

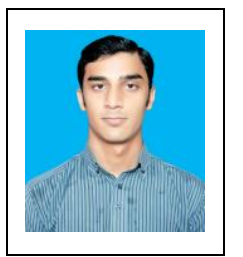

Safi Ullah Butt received his degree of B.Sc.in electrical engineering from Government College University Faisalabad (GCUF), Faisalabad, Pakistan in 2018. He received Gold Medal in B.Sc. of Engineering from GCUF, Faisalabad, Pakistan in 2018. He served as Teaching Assistant from 2016 to 2018 in GCUF during his B.Sc. He also served at Lahore polytechnic institute (LPI), Sheikhupura as an Electrical Instructor in 2018. He is currently pursuing M.Sc. in Electrical Engineerig at U.S. Pakistan Center of Advanced Studies in Energy(USPCAS-E),NUST Pakistan. His research interests include unmanned vehicle technologies, Android applications, high voltage insulators and high voltage engineering.

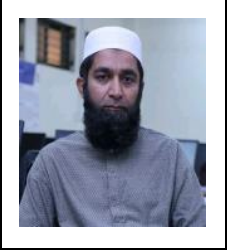

Abdul Rauf Bhatti received B.Sc. and M.Sc. degrees in electrical engineering from University of Engineering and Technology (UET), Lahore, Pakistan, in 2004 and 2008, respectively, and Ph.D. degree in electrical engineering from Universiti Teknologi Malaysia (UTM), Johor Bahru, Malaysia in 2017. He is currently working with Government College University Faisalabad (GCUF), 

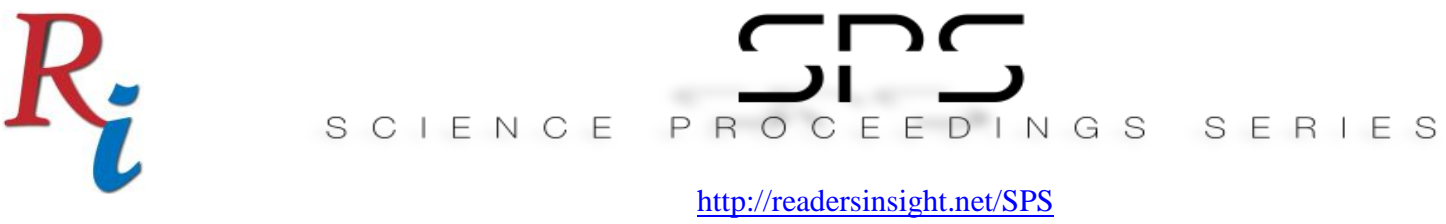

Faisalabad, Pakistan as an Associate Professor and Chairman of Electrical Engineering Department. He is serving the GCUF since 2006 at various posts like Lecturer and Assistant Professor. Before that he was with Government College of Technology, Faisalabad, Pakistan and Shakarganj Mills Ltd., Jhang, Pakistan in 2006 and 2005 respectively.

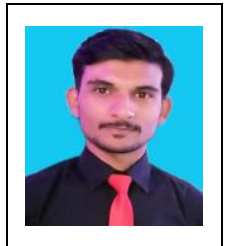

Bilal Ali received the degree of B.Sc. in electrical engineering from Government College University Faisalabad (GCUF), Faisalabad, Pakistan in 2018. He served as Teaching Assistant in GCUF, Faisalabad from 2015 to 2018. He received diploma of Associate Engineering (DAE) in Electrical from Government College of Technology, Faisalabad, Pakistan in 2014. He also served as Electrical Instructor at Fortune Institute of Advanced Studies in 2018. He is currently serving as Assistant Manager in Gohar Textile, Faisalabad, Pakistan. His research interests include unmanned vehicle technologies and power generation schemes.

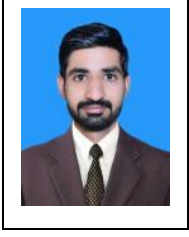

Ali Bashir received his degree of B.Sc. in electrical engineering from Government College University Faisalabad (GCUF), Faisalabad, Pakistan in 2018. He worked at Sitara Chemicals Ltd., Faisalabad, Pakistan and Nimra Textile Ltd., Faisalabad, Pakistan in 2018 and 2019 respectively. He also served at Klash Textile Ltd,. Faisalabad, Pakistan. He is the CEO of The Fokal company. His company produces electrical and electronics appliances for the household use.

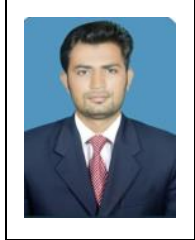

Muhammad Umar received his degree of B.Sc. in electrical engineering from Government College University Faisalabad (GCUF), Faisalabad, Pakistan in 2018. He served at Quetta Texile Mills Ltd., Pattoki, Pakistan and Pakistan Railway workshop, Lahore, Pakistan in 2018 and 2019 respectively. He also worked at Klash Textile Ltd,. Faisalabad, Pakistan. He received training in Applied Electrical Systems from Descon Technical Institute, Lahore, Pakistan. He is currently serving in Bestway Traders, Lahore, Pakistan.

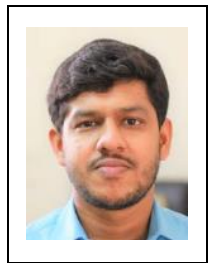

Taufeeq Liaquat did B.Sc. in electronic engineering from Islamia University Bahawalpur (IUB),Bahawalpur, Pakistan and M.Sc. in computer engineering from University of Engineering and Technology Taxila (UET),Taxila, Pakistan in 2007 and 2012 respectively. He is serving in Government College University Faisalabad (GCUF), Faisalabad, Pakistan since 2010 as a Lecturer. He is one of the most senior employees of the engineering faculty in GCUF, Faisalabad, Pakistan. He has expertise in Control systems in electrical engineering, Computer Communication Networks (CCN) and Linear Circuit Analysis. 